\title{
Álvaro Vega Sánchez. Del frío que azota al hogar común. Cuando azota el frío, EUNA, 2017
} Álvaro Vega Sánchez: From the cold that lashes the
common home. Cuando azota el frío, [When the cold hits]
EUNA, 2017 Álvaro Vega Sánchez: Do frio que castiga a casa comum.
Cuando azota el frío [Quando o frio fustiga] EUNA, 2017

Yadira Calvo-Fajardo Recibido: 15/06/2018

El primer contacto físico con un libro es la pasta y el primer contacto emocional e intelectual es con el título. Yo lo veo como la puerta de entrada de una casa. Pasada la puerta, está el vestíbulo. Ahí puede haber unas macetas, una banquita, un florero. En el caso de un libro, una dedicatoria, una introducción, un prólogo. Y un poco más allá, cuando nos hacen pasar a la sala, está el carácter, el estilo. La sala anuncia un modo de ser, el mensaje que sus habitantes nos quieren transmitir. A veces una señal de aviso: la Biblia en un atril (por supuesto, nunca el Kamasutra o el Decamerón). En un libro, los epígrafes corresponden a ese espacio de la sala en el que las visitas, antes de entrar en conversación, mirando cuadros, flores, retratos, se dan cuenta de la psicología de quienes viven allí. Se sientan, recorren el espacio con la mirada y juzgan. En el libro, más allá de las dedicatorias y los agradecimientos, vemos los epígrafes: los leemos y entramos en comunicación con ellos, sea para asentir o para rechazar.

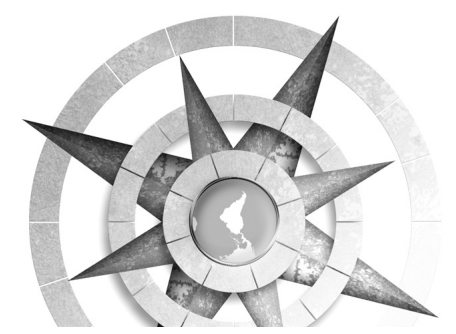

Con esto explico por qué cuando Álvaro me envió el manuscrito del libro que se presenta hoy, me fijé, desde luego, en el título. El título es un nombre. No es lo mismo llamarse Gunemunda o Sisebuto que llamarse Leonora o 
Roberto. Igual pasa con los títulos. Un buen título es sugerente. La expresión "cuando azota el frío" se me representa como el Cinco de Oros del tarot de Waite: dos figuras, una mujer y un niño renqueantes y sin abrigo, caminando bajo la nieve, y de fondo el vitral de un edificio sólido, tal vez una iglesia, que no los acoge. Es un símbolo de exclusión y de corporalidad sufriente. Ya sabemos de qué va. Por cierto que este título y la idea de este libro ya rondaban desde hace tiempo a su autor. En 2011, un artículo suyo publicado en el Semanario Universidad, se titula precisamente "Cuando azota el frío". En él critica "la frialdad humana y la incapacidad de la clase política para reconocer las dimensiones profundas de la crisis cultural de nuestro tiempo". Pero como decía John Steinbeck, "las ideas son como los conejos, tienes un par decentes y aprendes a manejarlas, y antes de darte cuenta tienes más de una docena". Así fue como el par de ideas que Álvaro manejó en aquel artículo se multiplicaron hasta alcanzar en este libro las dimensiones de un criadero.

Y esto importa, porque, citando a Erich Fromm, Vega nos recuerda que "la idea abre los ojos", nos despierta del letargo, nos fuerza a pensar y a sentir y a ver algo que antes no habíamos visto. Álvaro subraya: “...si llega a la gente se convierte en un arma de lo más poderosa porque crea entusiasmo y dedicación e incrementa y canaliza la energía humana".

Pero aún nos queda por ver el subtítulo; es decir, una aclaración, una cerca de piñuelas. Hay que cruzarla: "Globalización y Afectividad". Suena espinosa. Podría anunciar una monografía o un informe científico: datos, argumentos, "objetividad", muy "academia"; pero el título le impide anunciar eso, porque es una imagen literaria. Juntos los dos dicen que sí, que se trata de datos y argumentos pero que se trata también de sensibilidad, subjetividad, intuición y, por supuesto, voluntad de estilo. $\mathrm{O}$ sea que estamos ante un ensayo, ese que Alfonso Reyes denominó el "centauro de los géneros", y definió como "propio hijo caprichoso de una cultura que no puede ya responder al orbe circular y cerrado de los antiguos, sino a la curva abierta, al proceso en marcha, al 'etcétera".

Esto nos hace dirigirnos a los epígrafes: uno de Gabriela Mistral, otro de Jorge Debravo. La frase de Gabriela Mistral nos aconseja ver "detrás de la corteza de materia", la raíz de espíritu que la vivifica. Y el verso de Debravo nos ordena "arar con aros de fuego/ las eras del amor y el entusiasmo". Gabriela, la reflexión profunda y espiritual; Jorge, la acción, entusiasta 
y esperanzada. Ambos son los pilares de esta obra, que intenta fundir o al menos juntar y concordar todo lo que el pensamiento binario de nuestra cultura ha conservado desunido y opuesto. Ya no más artificialmente separados por un muro y marcados como superior e inferior, el pensar y el sentir, el cerebro y el corazón y, el varón y la mujer, la cultura y la naturaleza, el blanco y el negro. Un cambio verdadero necesita trascender esas oposiciones, porque, como señala Leonard Shlain (El alfabeto contra la diosa) refiriéndose a lo masculino y lo femenino, "un lado estaría incompleto sin el otro; juntos, forman un todo unificado que es más fuerte que cualquiera de las dos mitades". Y esto es válido para cualquier binariedad jerarquizada. Por ejemplo, para el arroz y las flores de la anécdota de Confucio que cita Álvaro: "iMe preguntas por qué compro arroz y flores? Compro arroz para vivir y flores para tener algo por lo que vivir".

En este sentido, Álvaro se inscribe dentro del cada vez más vasto grupo que se rebela contra esas viejas y gastadas formas de ver el mundo, revalorizando lo devaluado sin devaluar lo valorizado. Precisamente esta obra gira una y otra vez sobre las ideas de corporalidad, diversidad, afectividad, como manifestaciones deseables en un mundo diferente.
En ese plano del muro entre esto y aquello, la emoción es conceptuada como femenina y, por lo tanto, devaluada. Porque las canciones populares revelan el sentir popular, sin más argumentaciones recordemos el tango "Tomo y obligo". En él, un hombre lleno de pena invita a otro a acompañarlo a unos tragos: "Beba conmigo y si se empaña/ de vez en cuando mi voz al cantar/ no es que la llore porque me engaña/ Yo sé que un hombre no debe llorar". Precisamente contra ese tipo de prejuicios, Álvaro propone que "las emociones importan", que "en las ideas convergen lo racional y lo emocional", o sea, "la experiencia concreta de la corporalidad humana en su carácter constitutivo relacional y diverso".

Y aquí me vuelve a la cabeza la imagen del Cinco de Oros, con su corporalidad disminuida, imagen de la miseria y el desaliento, frente al poderío y la comodidad de quienes estén dentro del espacio protegido del edificio de los vitrales. Porque Álvaro habla de "la reivindicación y dignificación" de la corporalidad humana "diversa", la idea de entendernos y aceptarnos como sujetos corporales sensibles, "frente a un racionalismo frívolo e instrumentalista y un neoconservadurismo fundamentalista". 
Todo esto, enmarcado en una comunidad global, no en el sentido de globalización económica, sino en el de la "globalización afectiva", o sea, en el de la solidaridad, la equidad, la sostenibilidad y el pacifismo. Porque la afectividad contribuye -dice el autor- "a dignificar la corporalidad humana en su diversidad constitutiva y a la naturaleza biodiversa", y propicia "una convivencia democrática pluralista e inclusiva".

Estos son los grandes temas que entrelaza Álvaro en una obra que yo definiría como "sentipensante", en el sentido que a este término le dio su acuñador, Saturnino de la Torre, como "el proceso mediante el cual ponemos a trabajar conjuntamente pensamiento y sentimiento", uniendo dos conceptos tradicionalmente separados. Se trata de percibir e interpretar la realidad a partir de la reflexión y el impacto emocional, hasta converger en un mismo acto de conocimiento y acción. Sentipensar es el encuentro intensamente consciente entre sentimiento y razón. Y es que hay una comunidad universal, una "masa crítica" que está haciendo cambiar el mundo, rompiendo con las viejas formas de ver y creer. Este libro es parte de ella.

Leo a Álvaro y pienso por ejemplo, en Humberto Maturana, cuando plantea que "solamente el amor amplía la visión en la aceptación de sí mismo y del otro, a partir de las condiciones en que se vive y expanden las posibilidades de un operar más inteligente". Leo a Álvaro y pienso por ejemplo en David Servan Schreiber, quien sostiene que "en cada instante, el equilibrio de nuestro corazón influye en nuestro cerebro", al punto de que desde la cardiología y la neurología se ha llegado a hablar de un "sistema corazón-cerebro" indisoluble.

Este concepto de la afectividad y el de la dignificación de la corporalidad es la piedra de toque para la "globalización inclusiva" a que Álvaro se refiere. Porque es precisamente lo asentado en lo corporal lo que da pie a la exclusión: un cuerpo femenino, un cuerpo negro, un cuerpo indígena, un cuerpo lisiado, un cuerpo anciano, vistos con los cristales de la cultura excluyente, tuercen la mirada y mal informan sobre lo que hay "detrás de la corteza de materia", impidiendo ver la "raíz de espíritu" que los vivifica. En el caso de las mujeres, basta con leer a los filósofos más famosos desde Aristóteles hasta el siglo XX para darse cuenta del grado gigantesco en que la tuercen.

Pero con la intención de oponerse al frío que azota desde ahí, con una filosofía opuesta a la de "muerto el perro, se acabó la rabia" que ha 
venido aplicando la vieja visión, Álvaro apuesta por acabar con la rabia, arando con aros de fuego los campos de la dignidad y la inclusión, los de una nueva ciudadanía no violenta, dialogante y democrática, los de "la defensa de la vida desde una concepción bioecosistémica planetaria". Porque-dice Álvaro- "cuando azota el frío, hay que renovar la esperanza activa y "perseverante", que nos coloca en el umbral de las realidades posibles". "Crecer-afirma él- es fijar la mirada en un futuro siempre promisorio", en una "utopía realizable", porque "un mejor mundo es posible".

Recordemos que una vez al director de cine argentino Fernando Aguirre le preguntaron para qué servía la utopía. Según el relato de Eduardo Galeano, Aguirre contestó: "La utopía está en el horizonte. Y si está en el horizonte, yo nunca la voy a alcanzar. Porque si camino diez pasos, la utopía se va a alejar diez pasos; y si camino veinte pasos, la utopía se va a colocar veinte pasos más allá. O sea que yo sé que jamás nunca la alcanzaré. ¿Para qué sirve? Para eso, para caminar". Álvaro nos anuncia una utopía realizable en la que quepan los grupos excluidos y exiliados en su propia tierra, los "sin lugar". Pero una cosa es el "no lugar", u-topos de la utopía, y otra cosa el "sin lugar" de los grupos desheredados, los que se quedan fuera porque los de adentro les impiden entrar. Siguiendo la idea de Aguirre, buscamos lo primero porque nos ayuda a ir más allá; rechazamos lo segundo, porque entorpece el camino.

Tal vez el primer paso es ese que anuncia Álvaro: la afectividad como llave para lograr "sociedades globalizadas más solidarias, equitativas, sostenibles y pacíficas". Lo que en términos populares significa "ponerse en los zapatos del otro"; compadecer en el sentido etimológico de cum passio, una de cuyas interpretaciones es 'sufrir juntos'. Y esto es así no porque aspiremos a ello. Es así porque lo determina nuestra naturaleza: la comunicación afectiva -dice Servan Schreiber-, "el contacto emocional es, para los mamíferos, una auténtica necesidad biológica, como los alimentos y el oxígeno".

Puesto que una parte fundamental para cualquier cambio es entender que unidos, los dos términos de cualquier oposición constituyen una fuerza mucho más poderosa que las dos mitades, el planteamiento de Álvaro asume que en la idea de cambio hay, no obstante, una "fuerza fijadora". Y esa fuerza es la de la memoria. Recordar para repetir lo bueno; recordar para no repetir lo malo. Es el valor de la "memoria histórica" que reconstruye los sucesos para que los crímenes

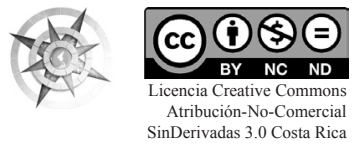

Álvaro Vega Sánchez. Del frío que azota al hogar común. 135

Cuando azota el frío, EUNA, 2017

Yadira Calvo-Fajardo 
no queden impunes, pero también porque, como dice Álvaro, el dolor de las víctimas indigna y sensibiliza. Y los seres indignados y sensibilizados "muestran el rostro esperanzador de una humanidad que no se ha dejado doblegar por el miedo y la represión".

Este es el núcleo sensitivo de los derechos humanos, y aquí tiene su espacio lo que Vega denomina la "globalización alternativa”, el gran ideal, la utopía, en que se incluye a todos los excluidos (por sexo, por raza, por etnia, por preferencia sexual, por lo que sea). Y con ellos a la naturaleza, excluida, abusada y maltratada como la que más.

"Los protagonistas de estas luchas sociales y políticas -advierte Vegamás que sustentar un discurso y una propuesta 'ideológica' alternativa, son portadores de un "espíritu" que se expresa/corporeiza en un comportamiento colectivo-afectivo donde priva el interés particular por la emancipación y dignificación del sujeto humano como corporalidad diversa". Son grupos que "se afirman y reconocen como protagonistas" en los que "predominan las actitudes y acciones [...] que afirman al colectivo como sujeto político. Es algo así como decir: "yo lo padezco, yo lo soluciono"; "No me proteja, que ya me protejo yo de usted".
Álvaro vuelve una y otra vez a la idea clave de su discurso, al núcleo generador del cambio, la "corporalidad sensible y diversa", lo que nos hace recordar la advertencia de Teilhard de Chardin respecto de que no somos seres humanos viviendo una experiencia espiritual, sino seres espirituales viviendo una experiencia humana. En otras palabras, lo de Gabriela: una raíz de espíritu detrás de la corteza de materia. Por lo tanto, la corteza importa.

Bueno, y como aquí mi compromiso era el de contar mi paseo a lomos de este centauro a trote hacia el etcétera, pues esto es, en resumen, lo que vi y entendí. Al final me queda la idea de que Álvaro es un soñador con mucha fe, pero, como dijo alguien de nombre impronunciable (Friedensreich Hundertwasser): "cuando alguien sueña en solitario es solo un sueño", y cuando "muchos sueñan juntos, es el comienzo de una nueva realidad". Yo creo que este libro va a agregar muchos sumandos a esa suma de esperanza. Y confío plenamente en la idea de Saint Exupéry, de que "una piedra deja de ser una piedra en el momento en que alguien la mira con la idea de construir una catedral".

Universidad Nacional, 14 de junio 2018

136 Álvaro Vega Sánchez. Del frío que azota al hogar común. 